\title{
Resonancia magnética dinámica en un caso de síndrome del cordón medular posterior
}

\author{
Dynamic magnetic resonance imaging in a case \\ of posterior medullary cord syndrome
}

\author{
José Luis Alcocer Maldonado, * Luis Gerardo Domínguez Carrillo
}

Citar como: Alcocer MJL, Domínguez CLG. Resonancia magnética dinámica en un caso de síndrome del cordón medular posterior. Acta Med Grupo Angeles. 2021; 19 (2): 296-297. https://dx.doi.org/10.35366/100461

Masculino de 75 años, profesionista, quien acude por presentar inseguridad durante la marcha, de un año de evolución, la cual se ha acentuado paulatinamente, por lo que de manera previa ha consultado al menos cinco especialistas, quienes efectuaron el diagnóstico de ataxia de la marcha, habiendo sido estudiado con imágenes de resonancia magnética convencional y potenciales evocados somatosensoriales, derivándolo, el último, a rehabilitación.

A la exploración se encuentra postura con cifosis dorsal e hiperlordosis cervical, nervios craneales normales, presencia de Romberg positivo, marcha con aumento en base de sustentación, inseguridad importante para realizar marcha en "tándem", la cual resulta imposible de efectuar con hiperextensión de columna cervical. Fuerza muscular de las cuatro extremidades en 5/5 en escala de Daniels, reflejos miotáticos disminuidos en miembros inferiores, pérdida de la sensibilidad propioceptiva, epicrítica y vibratoria por debajo de C7, pulsos y llenado capilar normales, sin alteración de esfínteres, no Babinski ni Hoffman.

Con los datos clínicos se establece diagnóstico de síndrome de lesión del cordón medular posterior, específicamente del fascículo gracilis, sustentado en pérdida de
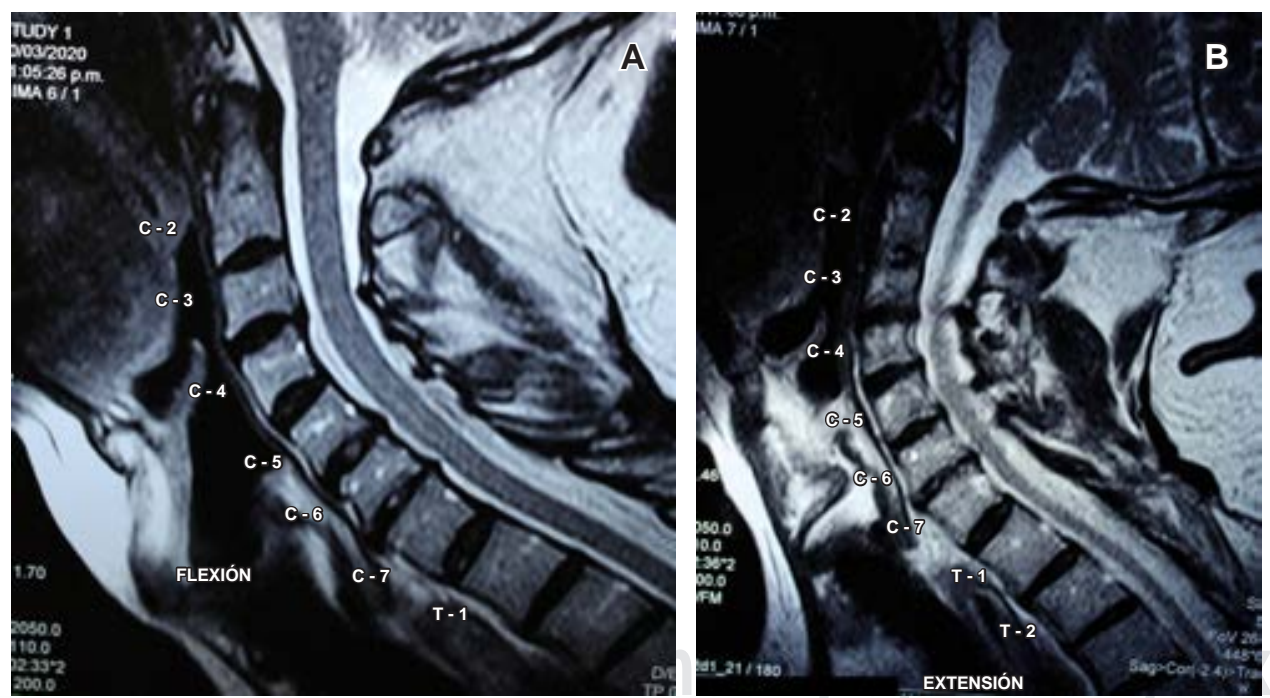

Figura 1:

Imágenes de resonancia magnética dinámicas de columna cervical ponderadas en T2. En flexión (A) se observa ligamento amarillo que origina compresión del saco dural. En extensión ( $B$ ) se exacerba la deformación del saco dural y la presión posterior sobre la médula cervical.

\footnotetext{
* Neurocirujano. División de Cirugía del Hospital Ángeles León, León, Guanajuato. México.

* Especialista en Medicina de Rehabilitación. Catedrático de la Facultad de Medicina de León, Universidad de Guanajuato. México.
}

Correspondencia:

Dr. Luis Gerardo Domínguez Carrillo

Correo electrónico: Igdomínguez@hotmail.com

www.medigraphic.com/actamedica

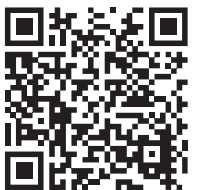


Figura 2:

Imagen de resonancia magnética de columna cervical en corte axial a nivel de C5 (A) muestra ingurgitación venosa (flechas) inmediatamente posterior a cordones posteriores medulares. B) Corte sagital que evidencia: plegamiento

de ligamento amarillo que deforman al saco dural (flechas).
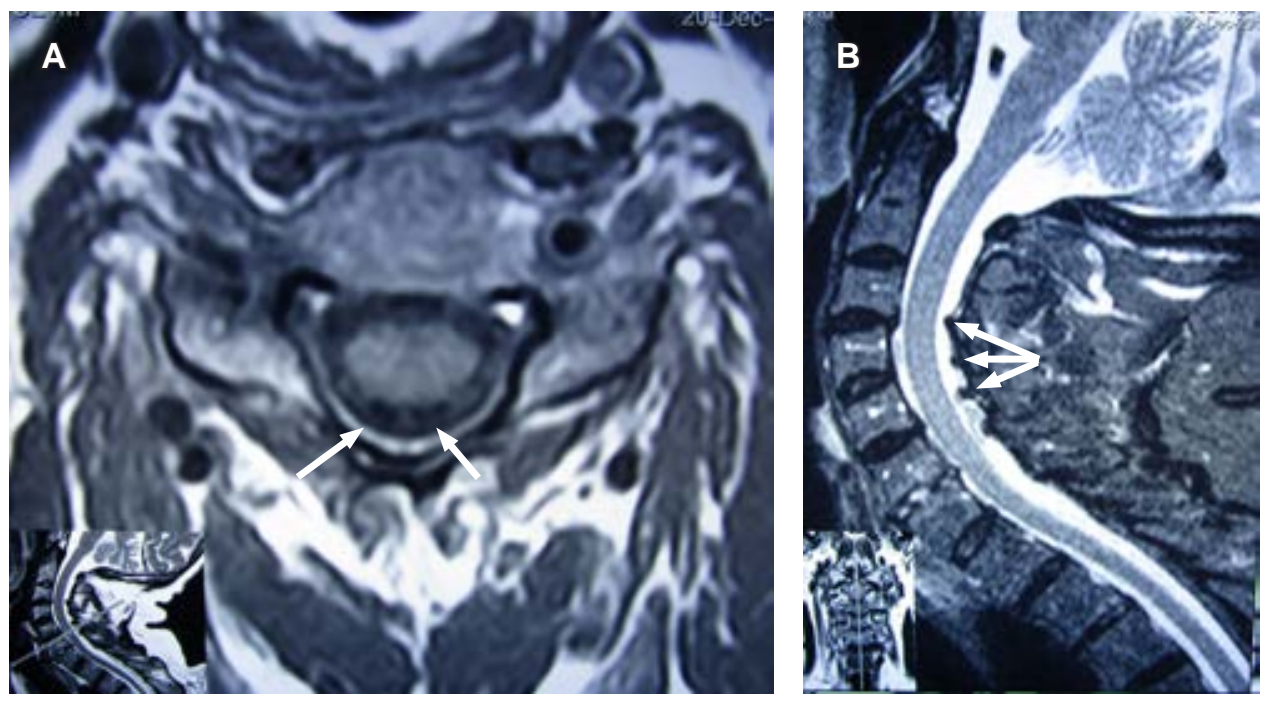

la sensibilidad propioceptiva, epicrítica y vibratoria por debajo de C7 y marcha atáxica con signo de Romberg positivo y miembros superiores normales, pues se consideró que el plegamiento del ligamento amarillo y de la duramadre pudieran contribuir a la compresión dorsal de la médula espinal en la hiperextensión, causando presión sobre la médula espinal. Por lo que se efectuó resonancia magnética cinética de columna cervical (Figuras 1 y 2), la cual confirmó el diagnóstico, por lo que se le programó para cirugía de columna cervical.

El síndrome de lesión del cordón medular posterior tiene frecuencia menor a $1 \%$. Se manifiesta mediante lesiones vertebrales causadas por compresión e hiperextensión, se le ha relacionado con oclusión de la arteria espinal posterior, tumores, compresión discal, deficiencia de vitamina B12 y con tabes dorsal.

La resonancia magnética cinética ( $k M R I$, por sus siglas en inglés) es una técnica de imagen que combina el excelente contraste de tejidos blandos y la capacidad multiplanar de la resonancia magnética (MRI) convencional con capacidades "funcionales" o cinemáticas, ya que permite que los pacientes sean examinados en múltiples posiciones. Se han utilizado diversas técnicas y dispositivos de posicionamiento para obtener estas imágenes de pacientes en posiciones de carga y carga de peso, en posición vertical y reclinada, y particularmente en flexión, neutra, extensión y rotación axial, las cuales demuestran la movilidad y la cinemática in situ que pue- den no ser evidentes con la resonancia magnética estática convencional. ${ }^{1}$

En cuanto a los cambios dinámicos del ligamento amarillo, en el estudio de Sayit y colaboradores, ${ }^{2}$ en el cual utilizaron kMRI en 257 pacientes, se observó que a medida que la columna cervical se mueve en flexión-extensión, el grosor del ligamento amarillo es significativamente mayor en extensión, en comparación con la flexión en los niveles C3-4, C4-5, C5-6 y C6-7, sin diferencias en los niveles C2-3 o C7-T1. Por lo que se concluye que kMRI puede demostrar hallazgos que no son evidentes en la resonancia magnética convencional y puede ser de gran utilidad en un entorno clínico cuando las técnicas convencionales de diagnóstico por imagen y diagnóstico no logran identificar la fuente de la patología cervical de un paciente. ${ }^{3}$

\section{REFERENCIAS}

1. Lord EL, Alobaidan R, Takahashi S, Cohen JR, Wang CJ, Wang BJ et al. Kinetic magnetic resonance imaging of the cervical spine: a review of the literature. Global Spine J. 2014; 4: 121-128. doi: 10.1055/s0034-1375563.

2. Sayit E, Daubs MD, Aghdasi B, Montgomery SR, Inoue H, Wang CJ et al. Dynamic changes of the ligamentum flavum in the cervical spine assessed with kinetic magnetic resonance imaging. Global Spine J. 2013; 3: 69-74. doi: 10.1055/s-0033-1337121.

Zhong G, Buser Z, Lao L, Yin R, Wang JC. Kinematic relationship between missed ligamentum flavum bulge and degenerative factors in the cervical spine. Spine J. 2015; 15: 2216-2221. doi: 10.1016/j. spinee.2015.06.048. 